Jurnal Ilmu-Ilmu Peternakan 26 (3): 20 - 26

ISSN : 0852-3681

E-ISSN : 2443-0765

CFakultas Peternakan UB, http://jiip.ub.ac.id/

\title{
Pengaruh citra merek (brand image) terhadap loyalitas konsumen bakso bakar Pak Man Kota Malang
}

\author{
Qauman Nur Syoalehat, Siti Azizah dan Anie Eka Kusumastuti \\ Fakultas Peternakan, Universitas Brawijaya, Malang \\ Jl. Veteran Malang 65145 Jawa Timur \\ Email : qauman24@yahoo.com
}

\begin{abstract}
This research was conducted in Bakso Bakar Pak Man from $7^{\text {th }}$ March to $5^{\text {th }}$ April 2016 through a survey method guided by a structured questionnaire. The respondents were selected using accidental sampling technique. The multiple linear regression analysis was used to analyse the data. The results showed that the characteristics of consumer were dominated by female students aged from 17-22 years old, lived in Malang and had monthly income > IDR. 2,000,000. Mostly, they got information about Bakso Bakar Pak Man from their families and friends. The brand image variables (corporate image, user image and product image) simultaneously influenced the consumers' loyality of "bakso bakar Pak Man”. It can be concluded that brand image variable which consisted of corporate image, user image and product image had a positive influence to the consumers' loyality of Bakso Bakar Pak Man. The most influential variable to "bakso bakar Pak Man"consumer's loyality was corporate image. It is recommended to "bakso bakar Pak Man" to maintain their service quality and product variant for increasing the consumer's interest and be acquainted with other media. The employee performance, product quality and facilities have to be improved in order to maintain the positive brand image of Bakso Bakar Pak Man.
\end{abstract}

Keywords: corporate image, user image, product image, consumer loyality

\section{PENDAHULUAN}

$\begin{array}{ccc}\text { Kota Malang terletak } 90 & \mathrm{~km} \\ \text { sebelah selatan } & \text { Surabaya dan }\end{array}$ merupakan kota terbesar kedua di Jawa Timur setelah Surabaya. Kota Malang berada di dataran tinggi yang cukup sejuk, dan seluruh wilayahnya berbatasan dengan Kabupaten Malang. Kawasan Malang Raya dikenal sebagai salah satu daerah tujuan wisata utama di Indonesia. Selain terkenal sebagai Kota Apel, Malang juga terkenal dengan kulinera bakso bakar yang telah berhasil menjadi primadona sajian kuliner khas kota Malang. Merek bakso yang dapat bertahan dalam persaingan bisnis yang cukup ketat adalah Bakso Bakar Pak Man Kota Malang. Bakso Bakar Pak Man merupakan warung bakso bakar yang didirikan tahun 1990an hingga saat ini.

Seiring berjalannya waktu, usaha bakso di Kota Malang semakin meningkat. Banyaknya pesaing dalam jenis usaha makanan ini secara tidak langsung menuntut produsen untuk lebih berkreasi menciptakan berbagai macam varian produk bakso yang 
menarik konsumen. Penetapan harga bakso oleh produsen juga akan mempengaruhi perilaku pembelian konsumen, sehingga produsen sebisa mungkin menyesuaikan harga jual produknya.

Pengusaha bakso harus bekerja keras untuk mempertahankan loyalitas konsumen karena semakin ketatnya persaingan secara tidak langsung akan mempengaruhi suatu usaha dalam mempertahankan pangsa pasar. Kotler dan Keller (2009) menyatakan bahwa loyalitas adalah kesetiaan konsumen untuk tetap membeli produk yang ditawarkan walaupun pesaing produk tersebut memberikan penawaran yang lebih baik dan memberikan alasan agar pelanggan beralih.

Pradipta (2012) menambahkan bahwa loyalitas tidak hadir begitu saja, sehingga diperlukan berbagai macam strategi dalam hal pengelolaan konsumen. Pengusaha harus mampu mengenal apa yang menjadi kebutuhan dan harapan konsumen saat ini maupun yang akan datang. Konsumen sebagai individu dalam mendapatkan atau membeli barang telah melalui prosesproses atau tahapan-tahapan terlebih dahulu, seperti mendapat informasi baik melalui iklan atau referensi dari orang lain (word of mouth) kemudian membandingkan produk satu dengan produk yang lain sampai akhirnya mengkonsumsinya dan berdasarkan pengalaman tersebut konsumen akan membeli produk yang sama (loyal). Penelitian ini bertujuan untuk mengetahui apakah citra merek dengan dimensi citra perusahaan, citra pemakai, dan citra produk berpengaruh positif terhadap loyalitas konsumen produk Bakso Bakar Pak Man.

\section{MATERI DAN METODE}

Penelitian ini dilaksanakan pada

Bakso Bakar Pak Man Kota Malang pada tanggal 7 Maret hingga 5 April 2016. Metode yang digunakan dalam kegiatan penelitian ini adalah survey. Jenis data yang diambil terdiri dari data primer dan data sekunder. Pengambilan data primer dilakukan melalui teknik wawancara menggunakan kuesioner terstruktur secara langsung dengan responden. Pengumpulan data sekunder atau pengumpulan data yang diperoleh secara tidak langsung juga dilakukan untuk melengkapi data primer. Penentuan lokasi penelitian menggunakan purposive sampling atau pemilihan tempat atau lokasi secara sengaja dengan pertimbangan bahwa Bakso Bakar Pak Man juga termasuk salah satu Bakso Bakar yang ramai dikunjungi di Kota Malang dan belum pernah dilakukan penelitian pada lokasi yang dipilih. Pengambilan data dilakukan dengan teknik accidental sampling hingga diperoleh 100 responden. Analisis data dilakukan secara deskriptif dan data statistik dianalisis dengan analisis regresi berganda melalui program SPSS 16.

\section{HASIL DAN PEMBAHASAN}

\section{Karakteristik konsumen}

Karakteristik konsumen Bakso

Bakar Pak Man Kota Malang didominasi oleh konsumen perempuan (60\%) pada cakupan usia 17-22 tahun (71\%) dan dari kalangan mahasiswa (54\%). Responden tersebut berdomisili di Kota Malang (58\%), dan sebagian besar (32\%) memiliki pendapatan berkisar diatas Rp. 2.000.000 per bulan. Konsumen mengetahui informasi Bakso Bakar Pak Man Kota Malang dari keluarga dan teman.

\section{Analisis dan pembahasan regresi linear berganda \\ Hasil regresi linier berganda dapat dilihat pada Tabel 1 .}


Tabel 1. Hasil analisis regresi linier berganda

\begin{tabular}{lcccr}
\hline \multirow{2}{*}{ Variabel } & \multicolumn{4}{c}{ Unstandardized coefficients $(\mathrm{B})$ Standardized Coefficients } \\
\cline { 2 - 3 } & $\mathrm{B}$ & Std. error & $(\beta)$ & \\
\hline Constant & $-3,106$ & 1,034 & & $-3,0030,003$ \\
Citra perusahaan & 0,313 & 0,094 & 0,357 & $3,3340,001$ \\
Citra pemakai & 0,364 & 0,120 & 0,267 & $3,0,340,003$ \\
Citra produk & 0,243 & 0,107 & 0,232 & $2,2790,025$ \\
\hline
\end{tabular}

Variabel dependen yaitu Loyalitas konsumen (Y) dan variabel independennya yaitu Citra perusahaan (X1), Citra pemakai (X2) dan Citra produk (X3). Model persamaan regresi linier berganda dari hasil analisis pada Tabel 15 sebagai berikut:

$Y=-3,106+0,313 X_{1}+0,364 X_{2}+0,243 X_{3}$ Interpretasi dari model persamaan hasil analisis regresi tersebut adalah sebagai berikut:

1. $\mathrm{a}=-3,106$

Nilai konstanta sebesar -3,106 bahwa semua variabel bebas (citra perusahaan, citra pemakai dan citra produk) memiliki nilai 0 (nol) maka nilai variabel terikat (loyalitas konsumen) sebesar -3,106.

2. $\mathrm{B}_{1=0,313}$

$\mathrm{X}_{1}$ sebesar 0,313 yang berarti citra perusahaan $\left(\mathrm{X}_{1}\right)$ berpengaruh positif terhadap loyalitas konsumen untuk mengkonsumsi bakso bakar Pak Man Kota Malang. Apabila variabel citra perusahaan naik maka loyalitas konsumen juga akan mengalami kenaikan sebesar 0,313. Sebaliknya apabila independensi turun maka loyalitas konsumen juga akan mengalami penurunan sebesar 0,313. Berpengaruhnya variabel citra perusahaan terhadap loyalitas konsumen mengindikasikan bahwa perusahaan itu sendiri merupakan hal penting bagi konsumen dalam melakukan pembelian. Salah satu alat untuk mengetahui loyalitas konsumen Bakso Bakar Pak Man yaitu dengan menganalisis karakteristik konsumen dan kesesuaian antara tingkat kepentingan menurut konsumen terhadap kinerja Bakso Bakar tersebut. Loyalnya konsumen secara tidak langsung mencerminkan seberapa jauh pihak Bakso Bakar Pak Man telah merespon keinginan dan harapan pasar. Pelayanan yang dilakukan sehari-hari oleh pihak Bakso Bakar Pak Man mencerminkan baik buruknya citra perusahaan didepan pelanggan.

\section{3. $\mathrm{B}_{2}=0,364$}

$\mathrm{X}_{2}$ sebesar 0,364 berarti bahwa citra pemakai $\left(\mathrm{X}_{2}\right)$ berpengaruh positif terhadap loyalitas konsumen untuk mengkonsumsi bakso bakar Pak Man Kota Malang. Apabila variabel citra pemakai naik maka loyalitas konsumen juga akan mengalami kenaikan sebesar 0,364 . Sebaliknya apabila citra pemakai turun maka loyalitas konsumen juga akan mengalami penurunan sebesar 0,364 .

\section{4. $\mathrm{B}_{3}=0,243$}

$\mathrm{X}_{3}$ sebesar 0,243 yang berarti citra produk $\left(\mathrm{X}_{3}\right)$ berpengaruh positif terhadap loyalitas konsumen untuk mengkonsumsi bakso bakar Pak Man Kota Malang. Apabila variabel citra produk naik maka loyalitas konsumen juga akan mengalami kenaikan sebesar 0,243 . Sebaliknya apabila citra produk turun maka loyalitas konsumen juga akan mengalami penurunan sebesar 0,243 . Berpengaruhnya variabel citra produk terhadap loyalitas konsumen mengindikasikan bahwa produk 
merupakan hal penting bagi konsumen dalam melakukan pembelian, sehingga produsen Bakso Bakar Pak Man diharapkan mampu meningkatkan segala aspek yang berkaitan dengan produk, baik dari segi kualitas, nama merek, varian maupun desain agar jumlah konsumen meningkat.

Berdasarkan hasil persamaan regresi tersebut bahwa variabel citra pemakai lebih berpengaruh terhadap loyalitas konsumen dengan koefisien 0,364 dan hasil uji $t_{\text {hitung yang diperoleh }}$ sebesar 3,034 dengan probabilitas 0,003 $(\mathrm{p}<0,05)$. Sedangkan variabel citra produk yang berpengaruh paling rendah koefisien 0,243 dengan hasil uji thitung yang diperoleh sebesar 2,279 dan probabilitas $0,025(\mathrm{p}<0,05)$. Hal ini menjadi dasar untuk menolak H0 dan menerima hipotesis yang menyatakan bahwa citra merek (brand image) berpengaruh signifikan terhadap loyalitas konsumen. Sehingga pelanggan mengkonsumsi produk Bakso Bakar tersebut atas dasar citra merek dari produk bakso itu lebih baik dari yang lainnya.

Hal ini sesuai dengan Permadi dan Kusumawati (2014), bahwa brand image merupakan prioritas penting bagi konsumen sebelum melakukan pembelian, dimana dengan adanya brand image positif di benak konsumen bisa menciptakan nilai lebih saat melakukan pembelian atau menggunakan suatu merek tertentu. Hal ini tidak sesuai dengan pernyataan Kurniawati dkk (2014) bahwa variabel citra merek tidak berpengaruh signifikan terhadap variabel loyalitas pelangganm imana pelanggan KFC mengkonsumsi produk tersebut karena kualitas produk bukan citra merek dari perusahaan.

\section{Uji hipotesis}

\section{Uji koefisien determinasi $\left(\mathbf{R}^{2}\right)$}

Hasil penelitian mengenai koefisien korelasi dan koefisien determinan dijelaskan pada Tabel 2.

Tabel 2. Koefisien korelasi dan koefisien determinasi $\left(\mathrm{R}^{2}\right)$

\begin{tabular}{ccccc}
\hline Model & $\mathrm{R}$ & $\mathrm{R}$ Square $\left(\mathrm{R}^{2}\right)$ & Adjusted R Square & Std. Error of the Estimate \\
\hline 1 & 0,751 & 0,565 & 0,551 & 1,76747 \\
\hline
\end{tabular}

Tabel 2 menunjukkan bahwa nilai koefisien determinasi $\left(\mathrm{R}^{2}\right)$ sebesar $56,5 \%$. Nilai R adjusted sebesar 55,1\% yang menunjukkan bahwa loyalitas konsumen di Bakso Bakar Pak Man Kota Malang dipengaruhi oleh faktor citra merek (brand image) sebesar $55,1 \%$.

\section{Uji F (uji serempak/simultan)}

Hasil uji F pada penelitian ini yang disajikan pada Tabel 3.

Tabel 3. Hasil uji F

\begin{tabular}{lccccc}
\hline \multicolumn{1}{c}{ Model } & Sum of Squares & Df & Mean Square & F & Sig. \\
\hline Regression & 388,850 & 3 & 129,617 & 41,491 & 0,000 \\
Residual & 299,900 & 96 & 3,124 & & \\
Total & 688,750 & 99 & & & \\
\hline
\end{tabular}

Hasil uji $\mathrm{F}$ diketahui bahwa $F_{\text {hitung }}$ sebesar 41,491 dan F-tabel dengan derajat bebas 3 dan 96 sebesar 2,699, maka $\mathrm{H}_{0}$ ditolak dan $\mathrm{H}_{1}$ diterima 
karena $F_{\text {hitung }}$ lebih besar dari $F_{\text {tabel }}$. Variabel citra merek yang terdiri dari citra perusahaan, citra pemakai dan citra produk berpengaruh signifikan terhadap loyalitas konsumen. Loyalitas konsumen terbentuk dengan adanya indikator-indikator merek yang memiliki ciri khas, dan merek dari produk dikenal luas sehingga konsumen merasa puas dengan menggunakan produk tersebut dan secara tidak langsung konsumen tersebut menyarankan orang lain untuk ikut menggunakan produk tersebut. Cornelia dan Nancy (2008) menyebutkan bahwa loyalitas akan terbentuk apabila seseorang sudah membandingkan produk yang digunakan dengan produkproduk lain yang sejenis dan kemudian merasakan bahwa kriteria produk tersebut sudah memenuhi keinginan mereka.

\section{Uji T}

Pengujian secara parsial dilakukan melalui uji t untuk menguji pengaruh variabel bebas secara terhadap variabel terikat. Hasil analisis uji t dapat dilihat pada Tabel 4.

Tabel 4. Hasil uji T

\begin{tabular}{lcccc}
\hline Variabel & $\mathrm{t}_{\text {hitung }}$ & $\mathrm{t}_{\text {tabel }}$ & Sig. & Keterangan \\
\hline Citra perusahaan & 3,334 & 1,985 & 0,001 & Hipotesis diterima \\
Citra pemakai & 3,034 & 1,985 & 0,003 & Hipotesis diterima \\
Citra produk & 2,279 & 1,985 & 0,025 & Hipotesis diterima \\
\hline
\end{tabular}

\section{Pengaruh citra perusahaan terhadap} loyalitas konsumen.

Hasil analisis diperoleh nilai $t_{\text {hitung }}(3,334)>t_{\text {tabel }}(1,985)$ dan nilai signifikansi $(0,001)<0,05$ sehingga $\mathrm{H}_{1}$ diterima. Citra perusahaan berpengaruh signifikan terhadap loyalitas konsumen. Nilai positif dari citra tidak akan ada dengan sendirinya tanpa adanya faktor kesengajaan dari perusahaan untuk menciptakan nilai positif tersebut. Sangat sulit bagi perusahaan untuk mempertahankan pelanggan yang sudah ada dan menarik pelanggan baru tanpa adanya citra merek yang kuat dan positif (Rizan dan Basrah, 2012).

Adona (2006) menyatakan bahwa citra perusahaan merupakan gambaran berbagai kegiatan sebuah perusahaan di mata para khalayaknya berdasarkan pengetahuan maupun pengalaman mereka sendiri. Apabila sebuah perusahaan meliliki citra yang positif dimata konsumen, maka akan membentuk sebuah loyalitas dalam pembelian produknya. Konsumen tidak hanya melihat kualitas dari produk tersebut, tetapi juga mempertimbangkan citra perusahaan pembuat produknya. Loyalitas sendiri mampu membuat konsumen memilih sebuah produk tertentu walaupun terdapat banyak pilihan produk dalam kategori produk yang sama (Giddens and Hofmann, 2011).

\section{Pengaruh citra pemakai terhadap loyalitas konsumen.}

Hasil analisis diperoleh nilai $t_{\text {hitung }}(3,034)>t_{\text {tabel }}(1,985)$ dan nilai signifikansi $(0,003)<0,05$ sehingga $\mathrm{H}_{1}$ diterima. Citra pemakai berpengaruh signifikan terhadap loyalitas konsumen karena adanya pengaruh indikatorindikator dari citra pemakai itu sendiri. Pratiwi dkk (2014) menyatakan bahwa citra pemakai merupakan sekumpulan asosiasi yang dipersepsikan konsumen terhadap pemakai yang menggunakan barang atau jasa, meliputi pemakai itu 
sendiri, gaya hidup atau kepribadian dan status sosial.

Jika seseorang melihat pemakai dari sebuah produk menunjukkan citra yang positif, maka akan membentuk sebuah perilaku yang positif pula. Dalam hal ini individu tersebut akan memiliki loyalitas terhadap produk tersebut karena mengharapkan dirinya akan memiliki citra positif yang sama dengan pembeli lain dari produk tersebut. Loyalitas pelanggan merupakan ukuran yang dapat diandalkan untuk memprediksi pertumbuhan penjualan dan juga loyalitas pelanggan dapat didefinisikan berdasarkan perilaku pembelian yang konsisten (Griffin, 2005).

\section{Pengaruh citra produk terhadap loyalitas konsumen}

Hasil analisis diperoleh nilai $t_{\text {hitung }}(2,279)>t_{\text {tabel }}(1,985)$ dan nilai signifikansi $(0,025)<0,05$ sehingga $\mathrm{H}_{1}$ diterima. Citra produk secara parsial berpengaruh signifikan terhadap loyalitas konsumen, dimana konsumen merasa puas dengan kualitas produk yang disajikan. Adanya kepuasan dari konsumen memberikan nilai lebih, dimana konsumen akan melakukan pembelian ulang (loyal). Variabel citra produk dibentuk dari beberapa indikator yaitu merek, kualitas, fitur dan desain. Hal ini sesuai dengan yang dinyatakan oleh Engel dkk (1994) bahwa konsumen yang melakukan pembelian terhadap sebuah produk pasti akan menilai manfaat produk yang dibeli.

Berdasarkan hasil pemaparan diatas, dapat disimpulkan bahwa variabel citra perusahaan (X1), citra pemakai (X2) dan citra produk (X3) memiliki pengaruh yang positif dengan tingkat signifikan masing-masing terhadap variabel loyalitas konsumen (Y).

\section{KESIMPULAN}

Variabel citra merek yang meliputi citra perusahaan, citra pemakai dan citra produk berpengaruh positif terhadap loyalitas konsumen Bakso Bakar Pak Man Kota Malang. Variabel yang paling berpengaruh terhadap loyalitas konsumen Bakso Bakar Pak Man Kota Malang adalah citra perusahaan.

\section{SARAN}

1. Bakso Bakar Pak Man harus meningkatkan kualitas pelayanan dan desain atau varian produk sehingga akan terus menarik konsumen dan lebih dikenal oleh media lainnya.

2. Kinerja karyawan, kualitas produknya dan fasilitas harus lebih ditingkatkan agar nama besar Bakso Bakar Pak Man terus dikenal positif oleh masyarakat.

\section{DAFTAR PUSTAKA}

Adona, F. 2006. Citra dan kekerasan dalam iklan perusahaan di televisi. Andalas University Press. Padang

Cornelia, E. S. dan Nancy, V. S. 2008. Analisa pengaruh kualitas layanan terhadap loyalitas pelanggan di Laundry 5asec. Surabaya. Jurnal Manajemen Perhotelan. Vol 4 (2). Hal 4547.

Engel, J. F. R. D., Ckwell dan Miniard. 1994. Perilaku konsumen. Terjemahan. Binarupa Aksara. Jakarta.

Giddens, N., dan Hofmann, A. 2011. "Brand loyalty (online)" http://www.extension.iastate.ed u/agdm/wholefarm. Diakses tanggal 20 Desember 2015.

Griffin, J. 2005. "Customer loyalty: Menumbuhkan dan Mempertahankan Kesetiaan 
Pelanggan”. Penerbit Erlangga. Jakarta

Kotler, P. dan Keller, K. L. 2009. Manajemen pemasaran. Edisi 12 Jilid 1. Indeks-Prentice Hall. Jakarta.

Kurniawati, D., Suharyono dan Andriani, K. 2014. Pengaruh citra merek dan kualitas produk terhadap kepuasan dan loyalitas pelanggan (Studi pada pelanggan KFC Cabang Kawi Malang). Jurnal Administrasi Bisnis.14 (2): 1-9

Permadi, K. S., dan Kusumawati, A. 2014. Pengaruh citra merek terhadap word of mouth dan keputusan pembelian (Survei pada konsumen Dapoer Mie Galau Jalan Selorejo 83
Malang). Jurnal Administrasi Bisnis. 10 (1): 1-7

Pratiwi, M. S., I Wayan, S., dan Ni, N. Y. 2014. Pengaruh citra perusahaan, citra produk dan citra pemakai terhadap keputusan pembelian produk Foremost pada Distro Ruby Soho di Singaraja. e-Journal Bisma Universitas Pendidikan Ganesha Jurusan Manajemen. 2: 1-12.

Rizan, M., dan Basrah, S. 2012. Pengaruh brand image dan brand trust terhadap loyalty teh botol sosro (Survei konsumen teh botol Sosro di Food Court ITC Cempaka Mas, Jakarta Timur). Jurnal Riset Manajemen Sains Indonesia (JRMSI). 3 (1): 1-17 